\title{
Uso ocular de água boricada: condições de manuseio e ocorrência de contaminação
}

\author{
Use conditions of boric acid solution in the eye: handling and occurrence \\ of contamination
}

\author{
Andrea Cotait Kara José ${ }^{1}$ \\ BrunoCastelo Branco ${ }^{2}$ \\ Lílian Emi Ohkawara ${ }^{3}$ \\ Maria Cecília Zorat $\mathbf{Y u}^{4}$ \\ Ana Luisa Höfling Lima ${ }^{5}$
}

Trabalho realizado no Departamento de Oftalmologia da Universidade Federal de São Paulo - UNIFESP.

${ }^{1}$ Médica estagiária dos Setores de Glaucoma e Doenças Externas do Departamento de Oftalmologia da Universidade Federal de São Paulo - UNIFESP - São Paulo (SP) - Brasil.

${ }^{2}$ Doutor em Oftalmologia pela UNIFESP - São Paulo (SP) - Brasil.

${ }^{3}$ Médica estagiária dos Setores de Glaucoma e Plástica Ocular do Departamento de Oftalmologia da UNIFESP - São Paulo (SP) - Brasil.

${ }^{4}$ Biomédica responsável pelo Laboratório de Doenças Oculares Externas e Infecções Exógenas da UNIFESP São Paulo (SP) - Brasil.

${ }_{5}^{5}$ Professora Titular e Chefe do Departamento de Oftalmologia da UNIFESP - São Paulo (SP) - Brasil.

Endereço para correspondência: R. Madre Teodora, 281

- São Paulo (SP) CEP 01428-010

E-mail: andreacotait@uol.com.br

Recebido para publicação em 03.10.2006

Última versão recebida em 19.11.2006

Aprovação em 20.11.2006

Nota Editorial: Depois de concluída a análise do artigo sob sigilo editorial e com a anuência do Dr. José Américo Bonatti sobre a divulgação de seu nome como revisor, agradecemos sua participação neste processo.

\section{RESUMO}

Objetivos: Avaliar as condições de uso de água boricada e verificar a contaminação dos frascos e seu conteúdo. Métodos: Foram selecionados, por critério de conveniência, quarenta e dois pacientes, usuários de água boricada, que compareceram ao Pronto-Socorro de Oftalmologia do Hospital São Paulo, em fevereiro e março de 2003. Foi colhido material para cultura do saco conjuntival, da superfície interna da borda do frasco, da superfície interna da tampa, além de $1 \mathrm{ml}$ de solução do frasco. Resultados: Dos 42 recipientes de água boricada, 17 (40,5\%) apresentavam contaminação, sendo $1(2,4 \%)$ no conteúdo liquido, $17(40,5 \%)$ na parte interna da tampa e $6(14,3 \%)$ na parte interna da borda do frasco. Dos 17 frascos contaminados, $10(58,8 \%)$ tiveram suas tampas manuseadas de maneira inadequada e $13(76,5 \%)$ frascos já haviam sido usados em outras ocasiões. Os microrganismos mais encontrados nas tampas e bordas foram Staphylococcus sp $(69,6 \%)$ e bacilos Gram-positivos $(26,1 \%)$. Dezesseis $(38,1 \%)$ frascos foram abertos há mais de um mês e, destes, 5 (31,3\%) apresentaram contaminação. A instrução de uso nos rótulos dos frascos era inconsistente. A utilização de água boricada foi por conta própria, por indicação de amigos ou parentes em 26 (61,9\%) casos; indicação de farmacêuticos em 8 (19,0\%); de oftalmologistas em $5(11,9 \%)$ e de clínicos gerais em 3 $(7,1 \%)$. Conclusão: A indicação de uso tópico oftálmico de água boricada foi feita, na maioria, por leigos. Os frascos, em geral, eram manipulados de maneira inadequada, apresentando contaminação em uma proporção de casos muito maior do que a contaminação do líquido. Essa porcentagem menor de contaminação do conteúdo provavelmente está associada às características anti-sépticas do produto.

Descritores: Contaminação de medicamentos; Soluções oftálmicas; Ácidos bóricos; Infecções oculares bacterianas; Conjuntiva; Infecções por Pseudomonas

\section{INTRODUÇÃ̃O}

Existe uma consideração especial em relação ao risco de ocorrência de contaminação de colírios, frascos de medicamentos e soluções oculares em uso, devido à possibilidade de veiculação de microrganismos potencialmente patogênicos para o olho ${ }^{(1-15)}$.

Diversas medidas devem ser tomadas para manter a esterilidade de produtos para uso ocular ${ }^{(16-17)}$. Os colírios, geralmente, contêm substâncias preservativas para manter a estabilidade da medicação e diminuir a possibilidade de contaminação ${ }^{(16-17)}$. Para reduzir a taxa de replicação de contaminante microbiano em colírios com formulação multidose e de uso domiciliar, 
recomenda-se o uso no máximo por um mês no caso de colírios com preservativos, enquanto os colírios sem preservativos, contendo alcalóide ou antibiótico, devem ser utilizados por até uma semana, desde que conservado sem temperatura entre 2 e $8^{\circ} \mathrm{C}^{(17-18)}$.

A água boricada é uma solução de ácido bórico cujo uso em diferentes condições oculares é bastante difundido em nosso meio, porém, não se observou na literatura estudo que mostre as condições de cuidado com os frascos desse produto, orientações quanto ao uso, suas indicações e a possível contaminação de seus frascos e conteúdo.

$\mathrm{O}$ ácido bórico é inorgânico com fórmula química $\mathrm{H}_{3} \mathrm{BO}_{3}$ e é usado medicinalmente como solução anti-séptica e de irrigação ocular, possuindo propriedade microbiostática nas primeiras 24 horas de exposição e propriedade microbicida após um maior período de uso ${ }^{(19-20)}$.

O ácido bórico é bem absorvido através da pele lesada e mal absorvido em pele íntegra ${ }^{(21-23)}$. A forma mais comum de intoxicação por ácido bórico é a absorção pela pele (22,24-25) $^{\text {Após a }}$ ingestão oral, o ácido bórico é rápida e altamente absorvido e sua intoxicação pode causar graves alterações sistêmicas, além de hiperemia conjuntival e "rash" cutâneo ${ }^{(24,26)}$. Exposição à poeira do ácido bórico provoca, comumente, irritação ocu$\operatorname{lar}^{(27)}$. Devido aos relatos de toxicidade, o uso de ácido bórico tópico é raramente disponível nos EUA e seu uso como solução anti-séptica e de irrigação foi abandonado pela classe médica americana ${ }^{(20)}$.

Para uso oftalmológico, o ácido bórico é apresentado em concentrações de até $5 \%$ em produtos vendidos sem prescrição médica ${ }^{(19)}$. O FDA ("Food and Drug Administration") julga questionável o uso tópico de ácido bórico com efetividade fungicida e anti-séptica ocular em concentrações de até $5 \%$ (28). Lentes de contato hidrofílicas contaminadas não ficam totalmente esterilizadas em soluções de ácido bórico ${ }^{(29)}$.

Este estudo avalia as condições de preservação, utilização e possibilidade de contaminação de frascos e conteúdo de água boricada usados para tratamento de afecções de pálpebra e conjuntiva por pacientes atendidos no Pronto-Socorro de Oftalmologia do Hospital São Paulo.

\section{MÉTODOS}

Foram selecionados, por critério de conveniência, quarenta e dois pacientes usuários de água boricada nos olhos e que compareceram ao Pronto-Socorro de Oftalmologia do Hospital São Paulo, nos meses de fevereiro e março de 2003.

Os indivíduos foram convidados a participar voluntariamente do estudo, respondendo ao questionário estruturado e providenciando o fornecimento do frasco de água boricada em uso em até três dias após a consulta inicial. No consentimento informado foi assegurado aos pacientes que a participação ou não na pesquisa não implicaria em diferenças no tratamento.

O questionário aplicado constava de sete questões relacionadas ao uso da água boricada, incluindo indicação, tempo e modo de uso, tempo de abertura do frasco, manuseio da tampa durante o uso, local de conservação do frasco e compartilhamento do produto (Anexo). Foram anotados tamanho do frasco $(\mathrm{ml})$, tipo de tampa, porcentagem e validade da água boricada.

Amostras de secreção do fundo de saco conjuntival inferior do olho mais sintomático ou do único olho em que se usou água boricada foram obtidas com zaragatoa estéril e alginatada umedecida em meio de cultura líquido de BHI ("Brain-Heart Infusion").

O cultivo inicial foi feito em meio de cultura líquido de BHI. A forma e técnica de colheita seguiram as normas já estabelecidas pelo Laboratório de Doenças Oculares Externas e Infecções Exógenas da UNIFESP-EPM (LOFT-UNIFESP) ${ }^{(30)}$.

Os frascos de água boricada e os tubos de BHI já inoculados com amostras da conjuntiva foram encaminhados ao LOFTUNIFESP. No laboratório, foram colhidas amostras da superfície interna da borda do frasco e da superfície interna da tampa dos frascos de água boricada com zaragatoa estéril e alginatada umedecida em BHI. Também foi submetido a cultivo $1 \mathrm{ml} \mathrm{de}$ solução de água boricada de cada frasco. A água boricada para cultivo foi retirada do frasco com uso de pipeta de Pasteur estéril. Os cultivos e a água boricada foram armazenados em tubos com meio BHI. No laboratório, a manipulação dos frascos de água boricada foi realizada em câmara com fluxo laminar.

\section{RESULTADOS}

Dos 42 pacientes que usavam água boricada, a média de idade observada foi de 39,05 anos, com desvio-padrão de 20,89. Não se observou predominância de alguma faixa etária, havendo $11(26,2 \%)$ indivíduos entre 0 e 20 anos, $13(31,0 \%)$ entre 21 e 40 anos, 10 (23,8\%), entre 41 e 60 anos e $8(19,0 \%)$ maior de 60 anos. (Quadro 1). Dos 42 pacientes, $24(57,1 \%)$ eram do sexo feminino.

Iniciais do nome: $\_$Questionário (Anexo)
Olho submetido ao uso de água boricada: __ Idade: __ Sexo: __
1. Pessoa que indicou o uso de água boricada:
2. Tempo de abertura do frasco:
3. Tempo de uso do frasco:
4. Forma de uso:
( ) Direto dentro do olho
( ) Compressa sobre o olho com pálpebras cerradas
( ) Compressa sobre o olho com pálpebras abertas
( ) Outras:
5. Uso do frasco: ( ) individual
6. Onde e como apóia a tampa do frasco durante o uso:
7. Local de conservação do frasco:




\begin{tabular}{|c|c|c|c|c|c|c|c|}
\hline$\#$ & $\begin{array}{l}\text { Idade } \\
\text { (anos) }\end{array}$ & $\begin{array}{l}\text { Tempo } \\
\text { abertura } \\
\text { frasco }\end{array}$ & $\begin{array}{l}\text { Tempo uso } \\
\text { frasco } \\
\text { (dias/meses) }\end{array}$ & $\begin{array}{c}\text { Contaminação } \\
\text { conjuntiva }\end{array}$ & $\begin{array}{l}\text { Contaminação } \\
\text { água boricada }\end{array}$ & $\begin{array}{c}\text { Contaminação } \\
\text { parte interna } \\
\text { frasco }\end{array}$ & $\begin{array}{c}\text { Contaminação } \\
\text { parte interna } \\
\text { tampa }\end{array}$ \\
\hline 1 & 56 & $25 d$ & $25 d$ & Staphyl. coag. neg. & Negativa & Negativa & Negativa \\
\hline 2 & 73 & $7 d$ & $7 d$ & Morganella morganii & Staphyl. aureus & Staphyl. aureus & Staphyl. aureus \\
\hline 3 & 50 & $6 m$ & $1 d$ & Staphyl. coag. neg. & Negativa & Negativa & Staphyl. coag. neg. \\
\hline 4 & 36 & $6 \mathrm{~d}$ & $6 \mathrm{~d}$, parou há $5 \mathrm{~d}$ & Staphyl. coag. neg. & Negativa & Staphyl. coag. neg. & Bacilos $\mathrm{G}_{+}$ \\
\hline 5 & 70 & $2 d$ & $2 d$ & Staphyl. coag. neg. & Negativa & Staphyl. coag. neg. & Staphyl. coag. neg. \\
\hline 6 & 14 & $4 m$ & $1 \mathrm{~m}$, parou há $3 d$ & Staphyl. coag. neg. & Negativa & Staphyl. aureus & Staphyl. coag. neg. \\
\hline 7 & 7 & $7 d$ & $7 d$ & Staphyl. aureus & Negativa & Negativa & Negativa \\
\hline 8 & 56 & $6 m$ & parou há 4m & Staphyl. coag. neg. & Negativa & Negativa & Morganella morganii \\
\hline 9 & 20 & $2 d$ & $2 \mathrm{~d}$, parou há $2 \mathrm{~d}$ & Staphyl. coag. neg. & Negativa & Negativa & Staphyl. coag. neg. \\
\hline 10 & 18 & $2 d$ & $2 d$ & Staphyl. coag. neg. & Negativa & Negativa & Negativa \\
\hline 11 & 31 & $10 \mathrm{~d}$ & $10 d$ & Staphyl. aureus & Negativa & Bacilos G+ & Staphyl. coag. neg. \\
\hline 12 & 63 & $8-10 a$ & $1 \mathrm{~m}$, parou há $4 \mathrm{~m}$ & Staphyl. coag. neg. & Negativa & Negativa & Negativa \\
\hline 13 & 39 & $5 \mathrm{~m}$ & 4d, parou há 1d & Staphyl. coag. neg. & Negativa & Negativa & Negativa \\
\hline 14 & 72 & $20 d$ & $10 d$, parou há $5 d$ & Staphyl. aureus & Negativa & Negativa & Staphyl. coag. neg. \\
\hline 15 & 22 & $9 m$ & 1d, parou há 2d & Staphyl. coag. neg. & Negativa & Negativa & Negativa \\
\hline 16 & 20 & $1 \mathrm{~m}$ & $1 d$, parou há $2 d$ & Staphyl. coag. neg. & Negativa & Negativa & Negativa \\
\hline 17 & 69 & $4 d$ & $2 \mathrm{~d}$, parou há $2 \mathrm{~d}$ & Staphyl. coag. neg. & Negativa & Negativa & Negativa \\
\hline 18 & 13 & $5 d$ & $5 d$ & Escherichia coli & Negativa & Negativa & Negativa \\
\hline 19 & 60 & $2 m$ & $60 d$, parou há 3d & Staphyl. coag. neg. & Negativa & Negativa & Negativa \\
\hline 20 & 21 & $6 m$ & $1 \mathrm{~m}$, parou há $2 \mathrm{~m}$ & Staphyl. coag. neg. & Negativa & Negativa & Negativa \\
\hline 21 & 49 & $6 d$ & 3d, parou há 3d & Staphyl. aureus & Negativa & Negativa & Staphyl. coag. neg. \\
\hline 22 & 28 & $5 d$ & $3 d$, parou há $2 d$ & Staphyl. coag. neg. & Negativa & Negativa & Bacilos $\mathrm{G}_{+}$ \\
\hline 23 & 52 & $3 d$ & $1 \mathrm{~d}$, parou há $1 \mathrm{~d}$ & Staphyl. coag. neg. & Negativa & Negativa & Staphyl. coag. neg. \\
\hline 24 & 54 & $1 \mathrm{a}$ & $2 d$, parou há $7 d$ & Staphyl. coag. neg. & Negativa & Negativa & Negativa \\
\hline 25 & 25 & $5 d$ & $4 d$, parou há $1 d$ & C. xerosis & Negativa & Negativa & Negativa \\
\hline 26 & 19 & $4 d$ & 1d, parou há 2d & C. xerosis & Negativa & Negativa & Staphyl. coag. neg. \\
\hline 27 & 35 & $2 a$ & $2 d$, parou há $13 d$ & Staphyl. coag. neg. & Negativa & Staphyl. coag. neg. & Staphyl. coag. neg. \\
\hline 28 & 30 & $1 \mathrm{~m}$ & $3 m$, parou há $1 d$ & Staphyl. aureus & Negativa & Negativa & Negativa \\
\hline 29 & 66 & $6 \mathrm{~d}$ & $6 d$ & Morganella morganii & Negativa & Negativa & Bacilos G+ \\
\hline 30 & 11 & $3 m$ & $1 \mathrm{~d}$, parou há $1 \mathrm{~m}$ & Staphyl. coag. neg. & Negativa & Negativa & Bacilos G+ \\
\hline 31 & 86 & $14 d$ & $14 d$ & Staphyl. aureus & Negativa & Negativa & Negativa \\
\hline 32 & 13 & $7 d$ & $5 d$, parou há $2 d$ & Staphyl. coag. neg. & Negativa & Negativa & Negativa \\
\hline 33 & 63 & $4 d$ & $4 d$, parou há $1 d$ & Streptococcus viridans & Negativa & Negativa & Negativa \\
\hline 34 & 39 & $15 d$ & $15 d$ & C. xerosis & Negativa & Negativa & Negativa \\
\hline 35 & 40 & $5 d$ & $2 d$, parou há $1 d$ & Staphyl. coag. neg. & Negativa & Negativa & Negativa \\
\hline 36 & 50 & $7 d$ & 3d, parou há 4d & Staphyl. coag. neg. & Negativa & Negativa & Negativa \\
\hline 37 & 41 & $14 d$ & $3 d$, parou há $11 d$ & Staphyl. aureus & Negativa & Negativa & Negativa \\
\hline 38 & 23 & $3 m$ & $3 d$ & Bacilos G+ & Negativa & Negativa & Negativa \\
\hline 39 & 54 & $4 d$ & $4 d$ & Staphyl. coag. neg. & Negativa & Negativa & Negativa \\
\hline 40 & 13 & $1 \mathrm{~m}$ & $1 \mathrm{~m}$ & Staphyl. aureus & Negativa & Negativa & Negativa \\
\hline 41 & 21 & $14 d$ & $14 d$ & Staphyl. coag. neg. & Negativa & Negativa & Bacilos $\mathrm{G}_{+}$ \\
\hline 42 & 18 & $1 \mathrm{~m}$ & $4 d$, parou há $2 d$ & Staphyl. coag. neg. & Negativa & Negativa & Negativa \\
\hline
\end{tabular}

Dos 42 recipientes de água boricada, 17 (40,5\%) apresentaram contaminação em alguma de suas partes, sendo $1(2,4 \%)$ no conteúdo líquido, $17(40,5 \%)$ na região interna da tampa e 6 $(14,3 \%)$ na região interna da borda do frasco (Quadro 1). Dentre as 17 tampas contaminadas, $10(58,8 \%)$ eram apoiadas com a abertura para baixo ou de qualquer maneira durante o uso. Destas 10 tampas, 4 (40,0\%) faziam parte de frascos com bordas internas contaminadas.
Dos 17 frascos contaminados, 4 (23,5\%) foram usados por indivíduos entre 0 e 20 anos, 5 (29,4\%), entre 21 e 40 anos, 4 $(23,5 \%)$, entre 41 e 60 anos e $4(23,5 \%)$, por maiores de 60 anos (Quadro 1).

Na única amostra de conteúdo de água boricada contaminada foi isolada a bactéria Staphylococus aureus, da mesma forma que na parte interna da tampa e na borda do frasco, enquanto que na conjuntiva do usuário foi encontrada a bac- 
téria Morganella morganii. Esse frasco estava aberto há uma semana e a tampa foi apoiada de qualquer maneira durante o uso (Quadro 1).

As bactérias mais comumente encontradas nas tampas dos frascos foram: $11(26,2 \%)$ Staphylococcus $s p$, sendo $10(23,8 \%)$ Staphylococcus coagulase negativo e $1(2,4 \%)$ Staphylococcus aureus, seguidas de $5(11,9 \%)$ bacilos Gram-positivos e 1 $(2,4 \%)$ bacilo Gram-negativo (Morganella morganii). Nas bordas dos frascos, foram encontradas 5 (11,9\%) Staphylococcus sp, sendo $3(7,1 \%)$ Staphylococcus coagulase negativo e $2(4,8 \%)$ Staphylococcus aureus, seguido de $1(2,4 \%)$ bacilo Gram-positivo (Quadro 1).

Foram isoladas bactérias em todas as conjuntivas, sendo encontradas 26 (61,9\%) Staphylococcus coagulase negativo e $8(19,0 \%)$ Staphylococcus aureus, seguidas de $3(7,1 \%)$ Corynebacterium xerosis, 2 (4,8\%) Morganella morganii, 1 $(2,4 \%)$ bacilos Gram-positivos, 1 (2,4\%) Streptococcus viridans e $1(2,4 \%)$ Escherichia coli (Quadro 1).

Dezesseis $(38,1 \%)$ frascos estavam abertos há um mês ou mais, sendo que $3(7,1 \%)$ há um ano ou mais. Vinte e nove $(69,0 \%)$ frascos foram usados somente para a afecção ocular atual e $13(31,0 \%)$ em afecções oculares prévias. Dos 16 frascos abertos há mais de um mês, $5(31,3 \%)$ estavam contaminados e, dos 26 abertos há menos de um mês, $6(23,1 \%)$ estavam contaminados (Quadro 1).

Quatro frascos $(9,5 \%)$ apresentaram o prazo de validade vencido. Em todos esses frascos, o conteúdo líquido e a parte

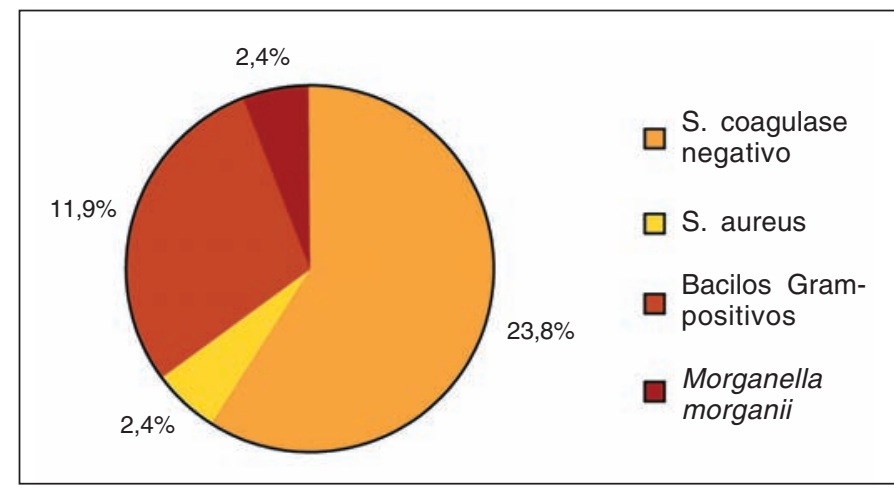

Figura 1 - Tipos de bactérias encontradas na tampa do frasco de água boricada

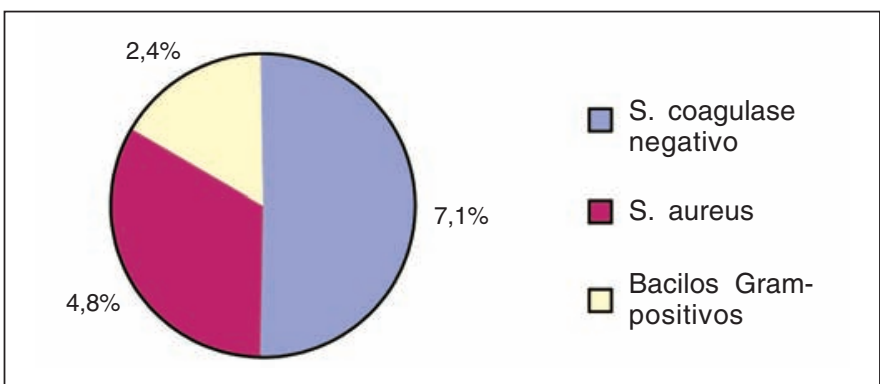

Figura 2 - Tipos de bactérias encontradas na parte interna da borda do frasco interna dos frascos não apresentaram contaminação bacteriana e em $2(50,0 \%)$, as tampas estavam contaminadas por bacilos Gram-positivos. As conjuntivas dos quatro pacientes apresentaram Staphylococcus coagulase negativo.

O tempo de validade registrado nas embalagens variou de dois a cinco anos, havendo, inclusive, variação entre frascos

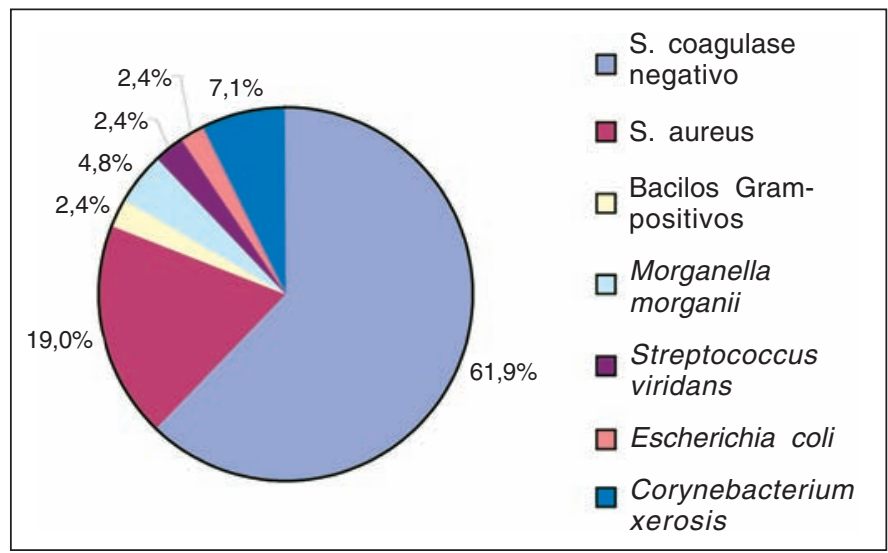

Figura 3 - Tipos de bactérias encontradas na conjuntiva dos usuários de água boricada

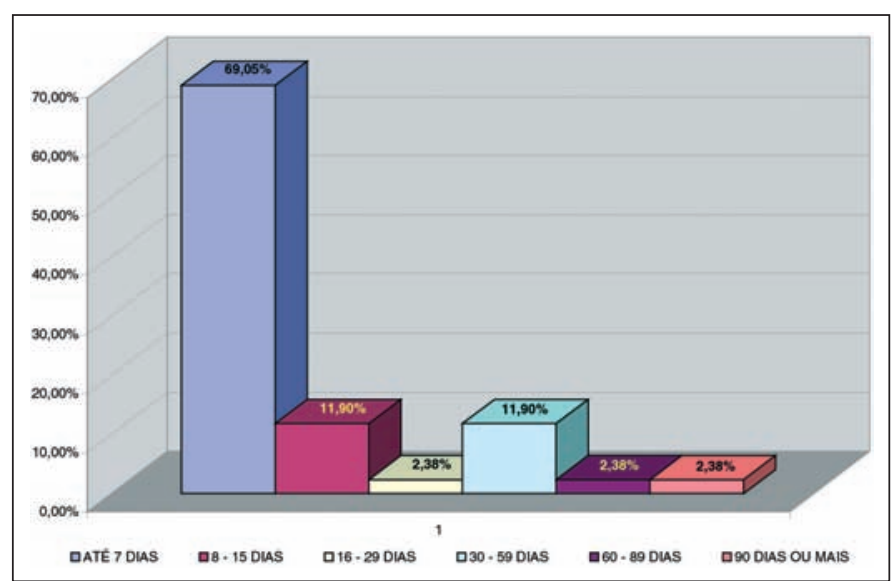

Figura 4 - Tempo de uso do frasco de água boricada

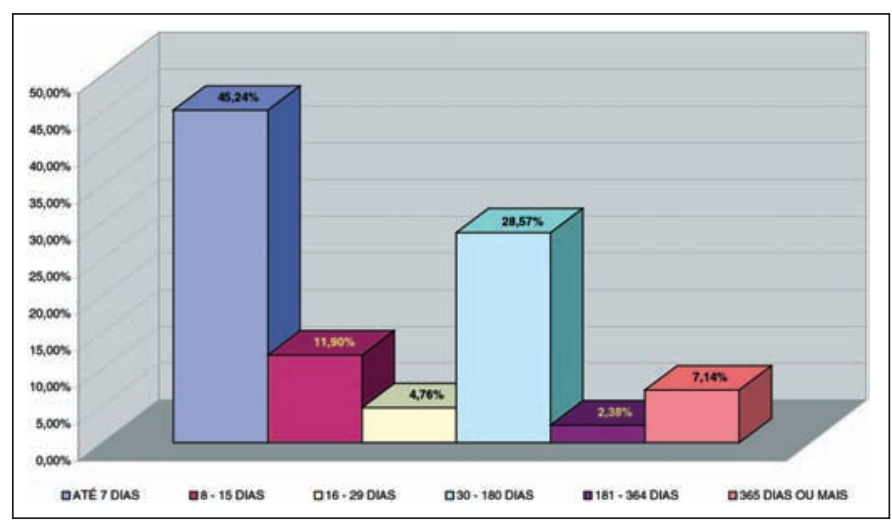

Figura 5 - Tempo de abertura do frasco de água boricada 
do mesmo laboratório. Não constam instruções quanto ao tempo de validade após a abertura do recipiente. Quanto à recomendação de uso de água boricada indicada nesses rótulos, todos mencionavam uso externo (tópico), sendo que 4 laboratórios $(9,5 \%$ do total de frascos) recomendavam aplicação direta nos olhos, 4 laboratórios $(9,5 \%$ dos frascos) indicavam compressa ocular e um frasco $(2,4 \%)$ não apresentava nenhuma orientação.

Os frascos continham água boricada a 3\%, a qual, segundo descrito em todos os rótulos, seria isenta de registro no Ministério da Saúde. Um frasco $(2,4 \%)$ apresentava capacidade de $90 \mathrm{ml} ; 24$ frascos $(57,1 \%)$, de $100 \mathrm{ml} ; 8$ (19,0\%), de $200 \mathrm{ml} \mathrm{e}$ $9(21,4 \%)$, de $250 \mathrm{ml}$.

Dos 42 pacientes, $19(45,2 \%)$ jogavam água boricada diretamente nos olhos, $3(7,1 \%)$ passavam algodão ou gaze na pálpebra aberta e $6(14,3 \%)$ faziam compressa com as pálpebras abertas.

Trinta e dois pacientes $(76,2 \%)$ usavam o frasco de água boricada individualmente e $10(23,8 \%)$, coletivamente. Dos 17 frascos contaminados, $2(11,8 \%)$ eram usados coletivamente.

Em relação ao modo de conservação, $24(57,1 \%)$ pacientes mantinham o frasco em geladeira e 18 (42,9\%), em locais sem refrigeração. Dos 17 frascos contaminados, 7 (41,2\%) eram mantidos em locais sem refrigeração.

A indicação de uso de água boricada foi por conta própria, por amigos ou parentes em 26 casos $(61,9 \%)$; por farmacêuticos em $8(19,0 \%)$; por oftalmologistas em $5(11,9 \%)$ e por clínicos gerais em $3(7,1 \%)$.

\section{DISCUSSÃO}

A contaminação de colírios e outras soluções de uso ocular é uma grande preocupação no meio oftalmológico ${ }^{(1-15)}$. As condições de manuseio e conservação de frascos de produtos de uso tópico oftálmico e suas tampas exigem conhecimentos específicos $^{(2-3,11,13,31-32)}$

Em nosso meio, é muito difundido o uso de água boricada em diferentes transtornos da superfície ocular e é importante a avaliação das condições de seu uso e possibilidade de contaminação.

Estudos mostram que a contaminação de colírios e soluções de irrigação em uso ocorre em ambiente hospitalar e consultórios oftalmológicos com freqüências de 0 a 54,0\% no conteúdo e 8,1 a $21,1 \%$ no frasco ${ }^{(1-3,9,13,32-33)}$. No ambiente doméstico é encontrada freqüência maior de contaminação, que varia de 8,0 a $76,0 \%$ no conteúdo e 11,3 a $27,0 \%$ no frasco $^{(8,10-11,15,34-35)}$.

Nos hospitais e clínicas onde, em geral, os funcionários são mais treinados para o manuseio com anti-sepsia, é esperado que ocorra menor contaminação desses produtos em relação aos usados por pacientes em ambientes domésticos ${ }^{(32)}$. Alguns autores mostraram que a taxa de contaminação de colírios diminui significantemente quando há orientação sobre o uso de procedimentos anti-sépticos ${ }^{(31)}$.
No presente estudo, foi verificado que muitos pacientes usaram o conteúdo dos frascos de água boricada já abertos por longos períodos para diferentes condições oculares, muitas vezes compartilharam a solução com mais pessoas e, em sua maioria, não possuíam conhecimentos sobre a maneira correta de diminuir a possibilidade de contaminação do produto.

A parte mais contaminada da água boricada de uso domiciliar foi os frascos $(40,5 \%)$, enquanto $1(2,4 \%)$ conteúdo liquido apresentou contaminação (Quadro 1). A taxa de contaminação em frascos foi maior do que a encontrada na maioria dos estudos em relação a outros produtos oculares de uso domiciliar ${ }^{(8,10-11,34)}$. Isso se deve provavelmente ao manuseio inapropriado da maioria dos frascos de água boricada pelos usuários. A porcentagem menor de contaminação do conteúdo de água boricada provavelmente está associada às características anti-sépticas do produto ${ }^{(19-20)}$.

Outros autores observaram 76,0\% de contaminação nas soluções de colírios de sangue autólogo em uso domiciliar, apesar de os pacientes terem recebido instruções escritas sobre aplicação do colírio e sobre a necessidade da conservação destes sob refrigeração ${ }^{(15)}$. Essa alta taxa de contaminação pode ser justificada pela facilidade de microrganismos crescerem nesse tipo de solução e pela ausência de soluções preservativas.

A contaminação dos frascos de produtos oftalmológicos pode ocorrer durante a instilação da substância, através do contato da ponta do frasco com uma superfície ocular externa, por meio das mãos do usuário ou de superfícies de apoio de tampas e conta-gotas ${ }^{(2-3,5,7,10-11,13,15,31,36-37)}$. As bordas e principalmente as tampas de frascos servem como reservatórios e fontes de microrganismos, podendo ocasionar contaminação das soluções $^{(2,5,7,8,10,13,38)}$.

As bactérias encontradas nos frascos de água boricada foram: 16 (69,6\%) Staphylococcus sp, sendo 3 (13,0\%) Staphylococcus coagulase positivo e $13(56,5 \%)$ Staphylococcus coagulase negativo, seguidas de $6(26,1 \%)$ bacilos Gram-positivos e $1(4,3 \%)$ Morganella morganii. Com exceção da Morganella, esses microrganismos são encontrados comumente na flora normal da conjuntiva e das pálpebras ${ }^{(2,6-8,10,13,15,17,27,36,38)}$.

Nos casos em que houve contaminação dos frascos de água boricada, não se observou concordância entre os germes presentes nos frascos e os presentes nas conjuntivas dos usuários. A contaminação, então, pode ter ocorrido pelo manuseio inadequado dos frascos através do contato das suas pontas com microorganismos das margens palpebrais, dos cílios, dos anexos oculares, das mãos dos usuários e/ou das superfícies de apoio das tampas.

Alguns autores mostraram que Staphylococcus coagulase negativo foi a principal bactéria isolada do conteúdo e da ponta dos frascos de produtos de multiuso ocular ${ }^{(2,10)}$. Os outros microrganismos encontrados também foram similares aos da flora normal da pele e conjuntiva, o que indica que a maioria dos microrganismos se originou por contaminação da ponta dos recipientes ${ }^{(2,10)}$. Outros autores observaram cultura positiva em $21,1 \%$ dos colírios e constataram que as partes mais contaminadas dos frascos foram a tampa (68\%) e a ponta dos frascos $(86 \%)^{(10)}$. 
A indicação para o uso de água boricada foi feita por oftalmologista em $11,9 \%$ dos casos e em grande parte por iniciativa própria, amigos ou parentes $(61,9 \%)$ e farmacêuticos (19,0\%). A frequiência de indicação por iniciativa própria, amigos ou parentes mostra o hábito de uso dessa substância em diferentes condições oculares. E a recomendação de farmacêuticos sinaliza que estes continuam a indicar tratamento sem estarem preparados; tendência em nosso meio, a qual foi identificada em estudo anterior ${ }^{(39)}$.

A água boricada é vendida livremente, o que não estimula nenhum tipo de cuidado quanto a seu uso. Tal constatação pode ser evidenciada pelo fato de $28(66,7 \%)$ usuários aplicarem o produto diretamente nos olhos ou limparem as pálpebras e fazerem compressas com os olhos abertos.

Além disso, os rótulos dos frascos de água boricada, ao contrário das demais soluções de uso ocular, para as quais existe obrigatoriedade de informações claras, apresentam poucas e contraditórias recomendações sobre seu uso e tempo de validade do produto.

Os frascos continham água boricada a $3 \%$ que, conforme descrito nos rótulos, é isenta de registro no Ministério da Saúde (Quadro 1). Esse posicionamento deve ser reavaliado, uma vez que os fármacos utilizados diretamente nos olhos devem se submeter aos mesmos cuidados recomendados para colírios e pomadas.

Estudos mostram que o uso de frascos grandes de soluções oculares, muitas vezes utilizadas durante meses em ambientes domésticos e de forma coletiva, apresenta maior possibilidade de contaminação $\mathrm{o}^{(9,37,40)}$. Na presente pesquisa, a taxa de contaminação dos frascos de água boricada ocorreu em diferentes tamanhos de frascos, usadas tanto coletivo como individualmente.

A incidência de contaminação dos frascos de água boricada não teve relação com o local de conservação (refrigerados ou não), com a validade do produto ou com a idade dos pacientes. Alguns estudos mostram a idade como fator de risco para contaminação de medicações oftálmicas, sugerindo menor habilidade dos idosos em instilar adequadamente as gotas dos colírios, fato que não ocorre com a água boricada, uma vez que esta normalmente não é instilada nos olhos como colírio ${ }^{(11)}$.

Não houve correlação relevante entre tempo de uso da água boricada e contaminação dos frascos e do conteúdo líquido. $\mathrm{Na}$ literatura, não há concordância em relação ao tempo de abertura dos recipientes e ao índice de contaminação ${ }^{(2,5,9,31)}$. Alguns autores mostram a existência de relação direta entre tempo de abertura e contaminação e recomendam a troca regular dos frascos ${ }^{(11,17,20,37)}$, enquanto outros não observam essa relação ${ }^{(2,6)}$. Os usuários de água boricada mantinham os frascos abertos por um intervalo de 2 dias a vários anos. Esse fato mostra a tendência de usuários de não desprezarem o frasco de água boricada já usado.

A solução para diminuição da contaminação de frascos e conteúdo de produtos de uso ocular requer, como preconizado por Schein et al. (1988), modificações tecnológicas, além da orientação e responsabilidade dos pacientes ${ }^{(6)}$.

\section{CONCLUSÃO}

A indicação de uso tópico oftálmico de água boricada foi feita, na maioria dos casos estudados, por leigos ou não especialistas. Os frascos eram manipulados de maneira inadequada, apresentando contaminação em uma proporção de casos muito maior do que a contaminação do líquido. Essa porcentagem menor de contaminação do conteúdo provavelmente está associada às características anti-sépticas do produto. Estudos "in vitro" poderão ser elaborados no intuito de definir os prazos de validade e as vias de contaminação de um produto tão usado pela nossa comunidade.

\section{ABSTRACT}

Purpose: To evaluate use conditions and detect contamination in bottles of boric acid solution. Methods: A convenience sample of 42 recruited patients using boric acid solution came to the Ophthalmology Emergency Room of the São Paulo Hospital from February to March of 2003. Cultures were taken from material of the conjunctival sac, inner surface of bottle edge, inner part of cap and from $1 \mathrm{ml}$ of boric acid solution of each bottle. Results: Of the 42 boric acid solution bottles, 17 $(40.5 \%)$ showed contamination: $1(2.4 \%)$ in the solution, 17 $(40.5 \%)$ in the inner cap and $6(14.3 \%)$ in the inner part of the bottle edge. Of the 17 contaminated bottles, 10 (58.8\%) were handled inappropriately and $13(76.5 \%)$ of the bottles were not discharged after first use. The most common microorganisms found in the caps and edges of the bottles were Staphylococcus sp (69.6\%), followed by Gram-positive bacillus $(26.1 \%)$. Sixteen bottles $(38.1 \%)$ had been opened more than a month ago and $5(31.3 \%)$ of those showed contamination. The boric acid solution bottle directions shown on the labels were incomplete and not clear. The use of boric acid solution was on recommendation of their own, friends or relatives in $26(61.9 \%)$ cases; pharmacists in $8(19.0 \%)$ cases, ophthalmologists in 5 $(11.9 \%)$ cases and general practitioners in $3(7.1 \%)$ cases. Conclusion: In most cases, the topic use of boric acid solution was recommended by non-physicians. The bottles, in general, were handled inappropriately, and hence presented a much higher level of contamination that did the boric acid solution inside. The lower level of contamination in the solution is possibly associated with the anti-septic characteristics of the boric acid solution.

Keywords: Drug contamination; Ophthalmic solutions; Boric acids; Eye infections, bacterial; Conjunctiva; Pseudomonas infections

\section{REFERÊNCIAS}

1. Vaughan DG Jr. The contamination of fluorescein solutions with special reference to Pseudomonas aeruginosa. (bacillus pyocyaneus). Am J Ophthalmol. 1955;39(1):55-61. 
2. Hovding G, Sjursen H. Bacterial contamination of drops and dropper tips of inuse multidose eye drop bottles. Acta Ophthalmol (Copenh). 1982;60(2):213-22.

3. Roizenblat J, Inomata S. Contaminação de colírios. Rev Bras Oftalmol. 1982; 41(1):55-9.

4. Templeton WC 3rd, Eiferman RA, Snyder JW, Melo JC, Raff MJ. Serratia keratitis transmitted by contaminated eyedroppers. Am J Ophthalmol. 1982; 93(6):723-6.

5. Coad CT, Osato MS, Wilhelmus KR. Bacterial contamination of eye drops dispensers. Am J Ophthalmol. 1984;98(5):548-51.

6. Schein OD, Wasson PJ, Boruchoff SA, Kenyon KR. Microbial keratitis associated with contaminated ocular medications. Am J Ophthalmol. 1988; 105(4):361-5.

7. Duffner LR, Pflugfelder SC, Mandelbaum S, Childress LL. Potential bacterial contamination in fluorescein-anesthetic solutions. Am J Ophthalmol. 1990; 110(2):199-202.

8. Schein OD, Hibberd PL, Starck T, Baker AS, Kenyon KR. Microbial contamination of in-use ocular medications. Arch Ophthalmol. 1992;110(1):82-5.

9. Stevens JD, Matheson MM. Survey of the contamination of eye drops of hospital in patients and recommendations for the changing of current practice in eye drop dispensing. Br J Ophthalmol. 1992;76(1):36-8.

10. Pereira IC, Alfonso E, Souza MACM, Song D, Muller D. Avaliação da contaminação de produtos oftálmicos em uso. Arq Bras Oftalmol. 1992;55(1):15-8.

11. Geyer O, Bottone EJ, Podos SM, Schumer RA, Asbell PA. Microbial contamination of medications used to treat glaucoma. Br J Ophthalmol. 1995;79(4): 376-9. Comment in: Br J Ophthalmol. 1996;80(3):270.

12. Kawakami LT, Prata Jr JA, Reys JC, Guidugli T, Mello PAA. Avaliação da contaminação bacteriana na mistura de colírios de fluoresceína e drogas anestésicas. Arq Bras Oftalmol. 1995;58(3):186-8.

13. Clark CPJ, Ong B, Stanley CCB. Contamination of diagnostic ophthalmic solutions in primary eye care settings. Mil Med. 1997;162(7):501-6. Comment in: Mil Med. 1997;162(10):632.

14. Höfling-Lima AL. Infecções oculares exógenas por bactéria, fungos e parasitas [tese]. São Paulo: Universidade Federal de São Paulo; 2000.

15. Höfling-Lima AL, Lima AS, Batistoso JA, Kawamura D, Chalita MRC, Alves LS, et al. Contaminação de frascos de colírios de soro autólogo. Arq Bras Oftalmol. 2001;64(1):63-5

16. Brown MRW. Control on infection in ophthalmic surgery. Control of contamination in ophthalmic solutions. Proc R Soc Med. 1967;60(4):354-7.

17. Oldham GB, Andrews V. Control of microbial contamination in unpreserved eye drops. Br J Ophthalmol. 1996;80(7):588-91. Comment in: Br J Ophthalmol. 1996;80(7):583-4.

18. British National Formulary. No 28. Control of microbial contamination. London: British Medical Association; 1994. p.399.

19. Houlsby RD, Ghajar M, Chaves G. Microbiologic characteristics of unpreserved saline. J Am Optom Assoc. 1998;59(2):184-8.

20. Siegel E, Wason S. Boric acid toxicity. Pediatr Clin North Am. 1986;33(2): 363-7.
21. Wester RC, Hui X, Hartway T, Maibach HI, Bell K, Schell MJ, ET AL. In vivo percutaneous absorption of boric acid, borax, and disodium octaborate tetrahydrate in humans compared to in vitro absorption in human skin from infinite and finite doses. Toxicol Sci. 1998;45(1):42-51.

22. Jordon JW, Crissey JT. Boric acid poisoning. A report of fatal adult case from cutaneous use. A critical evaluation of the use of this drug in dermatologic practice. AMA Arch Derm. 1957;75(5):720-8.

23. Ducey J, Williams DB. Transcutaneous absorption of boric acid. J Pediatr. $1953 ; 43(6): 644-51$

24. Goldbloom RB, Goldbloom A. Boric acid poisoning; report of four cases and a review of 109 cases from the world literature. J Pediatr. 1953;43(6):631-43.

25. Brooke C, Boggs T. Boric-acid poisoning; report of a case and review of the literature. AMA Am J Dis Child. 1951;82(4):465-72.

26. Schillinger BM, Berstein M, Goldberg LA, Shalita AR. Boric acid poisoning. J Am Acad Dermatol. 1982;7(5):667-73.

27. Garabrant DH, Bernstein L, Peters JM, Smith TJ. Respiratory and eye irritation from boron oxide and boric acid dusts. J Occup Med. 1984;26(8):584-6.

28. Beyer KH, Bergeld WF, Berndt WO. Final report on the safety assessment of sodium borate and boric acid. J. Am Coll Toxicol. 1983;2:87-125.

29. Uyeno MK, Hofling-Lima AL, Guidergli T, Uras R. Esterilização de lentes de contato hidrofílicas: estudo in vitro. Arq Bras Oftalmol. 1988;51(2):230-2.

30. Santos MP, Nishi M, Güntzel I, Lima ALH. Princípios básicos do diagnóstico das infecções oculares. In: Lima A, Melamed J, Calixto N, editores. Terapêutica clínica ocular. São Paulo: Roca; 1995. p.331-52.

31. Aslund B, Olson OT Sandell E. Studies on in-use microbial contamination of eye drops. Acta Pharm Suec. 1978;15(5):389-94.

32. Tamer HR, Sweet BV, Ross MB. Use and sterility of multidose ophthalmic medications. Am J Hosp Pharm. 1994;51(4):500-2.

33. Schellini SA, Silva MRBM, Gonçalves MRCB, Corrêa CR. Contaminação de colírios usados em ambiente cirúrgico. J Bras Med. 2000;78(1):10-6.

34. Porges Y, Rothkoff L, Glick J, Cohen S. Sterility of glaucoma medications among chronic users in the community. J Ocul Pharmacol Ther. 2004;20(2): 123-8.

35. Marion AD, Tampert MJ. Bacterial contamination of timolol in use by nonselected clinic population [abstract]. Invest Ophthalmol Vis Sci. 1986;27(1):36.

36. Harris MG, Gee A, Kusumoto, R, Lee H. Survival of contaminating bacteria in over-the-counter artificial tears. J Am Optom Assoc. 1996;67(11):676-80.

37. Fazeli MR, Nejad HB, Mehregan H, Elahian L. Microbial contamination of preserved ophthalmic drops in outpatient departments: possibility of an extended period of use. Daru. 2004;12(4):151-6.

38. Wilson LA, Schlitzer RL, Ahearn DG. Pseudomonas corneal ulcers associated with soft contact-lens wear. Am J Ophthalmol. 1981;92(4):546-54.

39. Kara José N, Helene A, Gomes de Deus PR, Caldato R, Pavero M. Atendimento de conjuntivite catarral aguda em farmácias nas cidades de Campinas e São Paulo. Arq Bras Oftalmol. 1983;46(2):178-82.

40. Raynaud C, Laveran H, Rigal D, Bonicel, P. [Bacterial contamination of eyedrops in clinical use]. J Fr Ophthalmol. 1997;20(1):17-24. French.

\section{ABO ELETROANIC \\ Oftalmologia com textos completos está disponível em:}

- ABD - Arquivos Brasileiros de Oftalmologia: http://www.abonet.com.br

- SciELD - Scientific Electronic Library Online: http://www.scielo.org

- Free Medical Journals - http://www.freemedicaljournals.com 